EGU21-11016

https://doi.org/10.5194/egusphere-egu21-11016

EGU General Assembly 2021

(c) Author(s) 2021. This work is distributed under

the Creative Commons Attribution 4.0 License.

\title{
Analysis of correlation between structural response and ground motion intensity measures.
}

Tariq Anwar Aquib, Jayalakshmi Sivasubramonian, and Paul Martin Mai

King Abdullah University of Science and Technology, Earth Science and Engineering Department, Saudi Arabia

(martin.mai@kaust.edu.sa)

Loss estimation for buildings that experienced earthquake shaking is an important step in Performance Based Earthquake Engineering (PBEE), comprising four major components - seismic hazard, building response, probability of damage, and the costs incurred in losses and repair works. The implementation of PBEE strongly depends on the ability to predict Engineering Demand Parameters (EDPs) that are usually defined in terms of maximum story drifts, plastic hinge rotations, and floor accelerations.

In this study, we compute building responses for large sets of recorded ground motions considering frames with different natural periods (0.1-1.5s). The ground motion data used in our analysis comprise near field records from moderate-to-large earthquakes; these may generate shaking levels high enough to be of concern for the design and safety of buildings. We select the frames by varying the number of storys and bays to obtain a wide range of natural building periods. We compute ground motion intensity measures (IM) from the recorded dataset and extract engineering demand parameters (EDP) from building response analyses. Our results indicate that the inter-story drift correlates strongly with spectral measures of ground motion intensity (correlation coefficient above 0.85 ). We also investigate the effect of natural period on the estimated correlations. We find that the correlations with spectral intensity measures do not strongly depend on Vs30 and epicentral distance. Our results are useful in the context of applied performance-based design of structures, especially if uncertainties in seismological parameters due to limited knowledge of source, site or path effects play an important role in earthquake ground motions. 